This is an Accepted Manuscript of an article published by Taylor \& Francis in 'Journal of American College Health' on 2019-03-25, available online: https://www.tandfonline.com/10.1080/07448481.2019.1583239.

\title{
Effectiveness of mindfulness-based coloring for university students' test anxiety
}

\section{Abstract}

Objective: This study compared the effectiveness of mindfulness coloring (mandala), free drawing/coloring, and a noncoloring control activity for university students' test anxiety, and assessed the relationship of dispositional mindfulness and response to intervention on mindfulness and test anxiety states. Participants: University students $(n=167 ; 81.4 \%$ female; $M_{\text {age }}=21.29$ years, $\left.S D=4.46\right)$ were randomly assigned to a mandala $(n=57)$, free draw/coloring ( $n=58)$, or noncoloring condition $(n=52)$. Methods: Participants completed standardized measures assessing test anxiety and state mindfulness pre-postactivity before completing a test, and two dispositional mindfulness measures. Results: Participants in both coloring conditions reported significant decreases in test anxiety and significant increases in state mindfulness prepostintervention, and participants in the control condition reported significant increases in test anxiety. Reports of preintervention state mindfulness and test anxiety fully mediated relations between dispositional mindfulness and postintervention state mindfulness and test anxiety.

Conclusions: Implications for research and practice on mindfulness coloring and test anxiety are discussed.

Mindfulness has been shown to be an increasingly effective strategy for supporting students' school-based anxiety. ${ }^{-}$Mindfulness involves a nonjudgmental attention, awareness, and acceptance of the present moment ${ }^{2}$ and recently, mindfulness-based activities have been incorporated in schools with elementary, secondary, and university students to support them in managing their test anxiety. $\stackrel{3-5}{-5}$ Approximately one-third of university students report experiences of test anxiety, $\stackrel{6-8}{ }$ which can include an immediate worry related to a testing situation (state test anxiety) and/or general concerns associated with testing..${ }^{9}$ Mindfulness-based art making 
This is an Accepted Manuscript of an article published by Taylor \& Francis in 'Journal of American College Health' on 2019-03-25, available online: https://www.tandfonline.com/10.1080/07448481.2019.1583239.

activities in particular have been found to be effective for reducing university students'

generalized anxiety compared with free draw/coloring activities $\underline{10}$ and for decreasing elementary and high school students' test anxiety., ${ }^{41}$ An example of a mindfulness-based art activity involves coloring structured mandalas (circles composed of symmetrical shapes), which have been included in many educational settings as coloring in the shapes enables an experience of focused attention and awareness of present moment experiences. 12

Although coloring in mandalas has been shown to be an effective mindfulness-based coloring activity for anxiety and test anxiety reduction, $, 10,13$ findings in the elementary and high school studies have been inconsistent with the previously conducted university studies. The university studies have found that coloring in mandalas is a more effective mindfulness-based activity compared with a free coloring/drawing activity ${ }^{10}$; however, other studies have shown that free coloring can be equally effective. ${ }^{14,15}$ Given that university students may struggle with higher test anxiety than youth $\frac{16,17}{17}$ an examination of the effectiveness of mindfulness coloring for test anxiety in a university setting is required. The purpose of this study is to evaluate the effectiveness of mindfulness-based coloring activities for university students' test anxiety.

Test anxiety is a concern among university students. In addition to reports that $33 \%$ of students are likely to experience test anxiety, $\stackrel{6-8}{-}$ this condition has been shown to be related to unhealthy behaviors (eg, increased alcohol consumption) $)^{1 \frac{18}{}}$ and outcomes $\frac{19}{}$ such as mental health challenges and other types of anxiety disorders, 2,21 poorer grades and academic performance, $\underline{22, \underline{23}}$ grade retention,,$\underline{24}$ and dropout. $\underline{25}, \underline{26}$ It is essential to include effective test anxiety reduction programs or activities for students ${ }^{27}$ to help prevent challenges resulting from test anxiety that may affect future academic performance and employment. $\underline{28-31}$ 
This is an Accepted Manuscript of an article published by Taylor \& Francis in 'Journal of American College Health' on 2019-03-25, available online: https://www.tandfonline.com/10.1080/07448481.2019.1583239.

Test anxiety can be measured as a trait (how students generally feel about testing situations); alternatively, test anxiety can be measured as a state (the anxiety experienced immediately prior to a testing situation). ${ }^{9}$ A number of interventions addressing students with state and trait test anxiety have been studied such as relaxation techniques, $\underline{32}$ cognitive and behavioral approaches, $\underline{\underline{27}}$ and expressive writing. $\underline{\underline{33}}$ More recently, mindfulness-based activities have been receiving attention in the research and school communities as strategies to help students manage anxiety and test anxiety, $\underline{13,34}$ and studies have shown that low reports of test anxiety are associated with higher mindfulness. $\cdot \underline{5}$ States of mindfulness (mindfulness experiences during particular moments in time) have been shown to increase following schoolbased mindfulness interventions. $\frac{36}{}$ Furthermore, dispositional mindfulness (one's tendency to experience mindfulness day-to-day) has been found to contribute to psychological well-being outcomes of mindfulness interventions, and higher levels of dispositional mindfulness are associated with frequent mindfulness state experiences. $\frac{37,38}{}$ In addition to examining the effectiveness of mindfulness interventions for test anxiety, it is important to also consider students' dispositional and states of mindfulness, which may be contributing to students' test anxiety and state mindfulness response when participating in a mindfulness-based intervention for test anxiety.

Researchers have begun to consider the effect of dispositional and state mindfulness on structured mandala coloring, which is a mindfulness-based strategy that has been evaluated for test anxiety reduction in the school setting. $.11,14$ Coloring structured mandalas is known to be a mindfulness-based art activity as it includes both elements of art making (eg, the creative manipulation of materials) and mindfulness meditation; $; 0,39$ specifically, when coloring in the intricate shapes of the structured design, individuals have the opportunity to experience a focused 
This is an Accepted Manuscript of an article published by Taylor \& Francis in 'Journal of American College Health' on 2019-03-25, available online: https://www.tandfonline.com/10.1080/07448481.2019.1583239.

awareness of their experience in the present moment. ${ }^{40}$ Unlike a free drawing or coloring activity in which students might feel anxiety and judgment of their product as they create their own structure, engaging in this structured design provides some type of direction in which individuals can organize their experience in that moment and develop mindfulness and focused attention and awareness, which can also be found in other types of meditation exercises., $, 10,41$

The first study to empirically assess the effectiveness of a structured mindfulness coloring activity was conducted by Curry and Kasser 10 and replicated by Van der Vennet and Serice. $\frac{13}{}$ University students were randomly assigned to a mandala coloring condition, a plaid form coloring condition, or a free coloring condition. All participants received an anxiety induction 20 min prior to coloring, and their general anxiety was assessed using the State-Trait Anxiety Inventory at baseline, prior to coloring, and immediately following coloring. In Curry and Kasser's study, participants ( $n=84 ; 65 \%$ female) reported significantly greater decreases in anxiety in both structured coloring conditions (mandala and plaid) compared to the free coloring condition. Participants in Van der Vennet and Serice's study ( $n=50 ; 82 \%$ female) reported significantly greater decreases in anxiety in the mandala condition compared to the plaid and free coloring condition; however, participants in the plaid and free coloring condition also showed reductions in anxiety. These studies did not examine test anxiety specifically; therefore, an examination of these coloring activities for test anxiety was required.

There has been recent evidence comparing the effectiveness of structured coloring of mandalas compared with free coloring for youth's test anxiety;, $, 11,14$ however, the effectiveness of this activity for adults' test anxiety has yet to be examined. The elementary and high school studies have shown benefits for test anxiety reduction and state mindfulness following $15 \mathrm{~min}$ of coloring - either mandala or free - and have also suggested that participants' reports of 
This is an Accepted Manuscript of an article published by Taylor \& Francis in 'Journal of American College Health' on 2019-03-25, available online: https://www.tandfonline.com/10.1080/07448481.2019.1583239.

dispositional mindfulness may be influencing their response to the intervention. Specifically, Carsley and Heath ${ }^{11}$ examined the effectiveness of mindfulness coloring and dispositional mindfulness on test anxiety. Participants were 193 Grade 8 students (56.6\% female) randomly assigned to mandala coloring, or a free draw/color condition for $15 \mathrm{~min}$. Participants completed the state version of the State Trait Anxiety Inventory and the Mindful Attention Awareness Scale (state MASS) short form pre-postintervention, as well as the Child and Adolescent Mindfulness Measure (CAMM) as a measure of dispositional mindfulness, prior to completing the spelling section of an achievement test. Results from this study revealed overall significant decreases in test anxiety and significant increases in state mindfulness for both conditions; however, females reported significantly greater decreases in test anxiety in the free condition compared to males. In addition, preintervention state mindfulness and test anxiety fully mediated relations between dispositional mindfulness and postintervention state mindfulness and test anxiety.

Although research has shown that increases in state mindfulness and mindfulness practice over time are associated with increased dispositional mindfulness in undergraduates and adults, $\underline{37,42}$ there is limited research examining the role of dispositional on state mindfulness as a response. In an examination of the moderating role of dispositional mindfulness on Mindfulness Based Stress Reduction (MBSR) intervention effects ${ }^{42}$ (eg, mental health outcomes), participants with higher dispositional mindfulness participating in an MBSR condition reported greater increases in mindfulness and subjective well-being and greater decreases in stress over time compared to those with lower dispositional mindfulness; however, the role of state mindfulness in this model was not considered. Results from Carsley et al ${ }^{11}$ suggest participants' mindfulness states and dispositions are influencing their immediate response to this intervention, as such, the 
This is an Accepted Manuscript of an article published by Taylor \& Francis in 'Journal of American College Health' on 2019-03-25, available online: https://www.tandfonline.com/10.1080/07448481.2019.1583239.

relationship between dispositional and state mindfulness as a response requires further examination.

In addition to youth, coloring mandalas and adult coloring books have been receiving a lot of attention in educational research in recent years with undergraduate students. A study examining the effectiveness of adult coloring books on undergraduate students' mental health outcomes revealed that coloring was more effective than logic puzzles. .43 Participants were 104 female university students, randomly assigned to a coloring condition which consisted of a coloring booklet with a number of complex designs (including mandalas), or a logic puzzle condition which consisted of a variety of puzzles (eg, word searchers, Sudoku, etc). Participants completed measures of depression, stress, anxiety, resilience, flourishing, and mindfulness at the beginning and end of the study, and completed the coloring activities over a 7-day period at their leisure, as well as daily measures of activity adherence, mental health, mindfulness, and flourishing. The postintervention survey was completed following the 7-day period, and participants in the coloring condition reported significant decreases in depression and anxiety when a conservative Bonferroni correction was applied. Participants in the logic puzzle condition only showed increases in mindfulness following the intervention.

More recently, Mantzios and Giannou ${ }^{15}$ evaluated the effectiveness of mandala coloring for increasing mindfulness and decreasing anxiety among university students. In their first experiment, participants $(n=88)$ were randomly assigned to an unguided mandala coloring condition or a free coloring condition for $10 \mathrm{~min}$. State mindfulness and state anxiety were assessed pre-postintervention with the State Anxiety Inventory, Short form, and the State Mindfulness Scale. Results revealed significant decreases in anxiety for both groups; however, 
This is an Accepted Manuscript of an article published by Taylor \& Francis in 'Journal of American College Health' on 2019-03-25, available online: https://www.tandfonline.com/10.1080/07448481.2019.1583239.

there were no significant changes in mindfulness pre-postintervention. According to the authors, proper guidance and intention is required for these activities to be considered as mindful. $\frac{15}{5}$

To further explore this suggestion, the authors compared the effectiveness of a 10-min unguided mandala coloring activity with a guided mandala coloring activity among 72 undergraduate students. Participants were randomly assigned to an unguided mandala coloring group in which they engaged in 10 min of mandala coloring, or a guided mandala coloring group in which a facilitator delivered guided instructions adapted from breathing meditations to participants while they colored their mandala for $10 \mathrm{~min}$. Results revealed significant decreases in anxiety in the guided condition, and no changes in mindfulness were found. These recent studies suggest that more research is required to examine the effectiveness of mandala coloring on state mindfulness. These studies did not include an adequate control group; therefore, the changes in anxiety and mindfulness that were found may simply be due to a repeated testing effect or the passage of time. It is critical to determine whether these activities should be considered mindfulness-based, and if they actually do differ from free coloring.

Findings from the elementary and high school research suggest that both structured mandala and free coloring activities are beneficial for decreasing test anxiety and increasing mindfulness; however, given the mixed findings in the initial university studies that structured mandala coloring may be more helpful than free coloring for anxiety reduction, $\underline{10,13}$ it is important to assess the effectiveness of these activities in the university setting for test anxiety to determine if developmental periods impacts response to the intervention. Given that the preadolescent and adolescent samples demonstrated that both coloring activities revealed similar outcomes in terms of test anxiety and state mindfulness, as well as the findings in the recent university study demonstrating that both mandala and free coloring are associated with decreases 
This is an Accepted Manuscript of an article published by Taylor \& Francis in 'Journal of American College Health' on 2019-03-25, available online: https://www.tandfonline.com/10.1080/07448481.2019.1583239.

in anxiety, $\frac{15}{1}$ it is also crucial to examine the effectiveness of these activities compared to a noncoloring control group to determine if university students can also benefit from free coloring for test anxiety, and whether free coloring is associated with mindfulness benefits.

The purpose of this study is to address this gap and evaluate the effectiveness of mindfulness-based coloring activities for university students' test anxiety. The first objective is to compare the effectiveness of a structured mindfulness coloring activity (mandala) and a free/draw coloring activity with a noncoloring control activity on decreasing test anxiety and increasing state mindfulness among university students prior to a test. It is hypothesized that students in the mandala and free conditions will report reductions in test anxiety (H1) and increases in state mindfulness (H2), while students in the noncoloring control group will not show this change. The second objective is to examine the impact of dispositional mindfulness on postintervention state mindfulness and test anxiety. It is hypothesized that participants' preintervention state mindfulness would mediate the relationship between dispositional mindfulness and postintervention state mindfulness (H3) and preintervention test anxiety would mediate the relationship between dispositional mindfulness and postintervention test anxiety (H4).

\section{Methods}

\section{Measures}

\section{State-trait anxiety inventory - state anxiety scale}


This is an Accepted Manuscript of an article published by Taylor \& Francis in 'Journal of American College Health' on 2019-03-25, available online: https://www.tandfonline.com/10.1080/07448481.2019.1583239.

The State-Trait Anxiety Inventory's State Anxiety Scale (STAI) is a self-report measure assessing adolescents', college students' and adults' current states of anxiety. ${ }^{44}$ The state scale comprises 20 items and participants report how they are feeling the moment they are responding to the questionnaire. Sample items include statements such as "I am worried" or "I feel upset" and participants circle their response on a 4 -point scale $(0=$ not at all; $4=$ very much so $)$. The majority of test anxiety measures assess traits of anxiety; therefore, to assess the immediate state of anxiety prior to a test, this particular measure was used. This particular measure has been used to assess states of test anxiety with high school students and Cronbach alphas ranged from 0.88 to 0.90 , with a test-retest correlation of $0.65 .^{11}$ In other studies, this measure has been found to be associated with high internal consistency $(\alpha=.86-.96)$ and scores ranging from .65 to .76 for test-retest reliability. ${ }^{45}$ In this study, Cronbach alphas ranged from .92 to .94 prepostintervention, with a test-retest correlation of .71 .

\section{MASS, state version}

The state MAAS, which assesses current states of mindfulness, is derived from Brown and Ryan's ${ }^{46}$ original MAAS. The original state MAAS is comprised of 5 items referring to a previous state-mindfulness experience (eg, "I was rushing through something without being really attentive to it"). For the purpose of this study, the state MAAS was adapted to assess participants' current and immediate state of mindfulness (eg, "Right now, I keep thinking about the future or the past."). Participants are instructed to use a 7-point scale to indicate how they feel at that moment from $0=$ not at all to $6=$ very much. Test-retest correlations from previous studies range from .66 to $.74 .11, \underline{14}$ In this study, Cronbach alphas ranged from .77 to .82 prepostintervention, with a test-retest correlation of .76 . 
This is an Accepted Manuscript of an article published by Taylor \& Francis in 'Journal of American College Health' on 2019-03-25, available online: https://www.tandfonline.com/10.1080/07448481.2019.1583239.

\section{Child and adolescent mindfulness measure}

The CAMM is a 10-item reverse-scored measure assessing children and adolescents' dispositional mindfulness. ${ }^{47}$ The questionnaire includes items assessing present moment awareness (eg, "I keep myself busy so I don't notice my thoughts or feelings") and nonjudgmental acceptance (eg, "I stop myself from having feelings that I don't like") and participants indicate how often an item is true for them on a 5-point scale $(0=$ never true; $4=$ always true $)$. In this study, the CAMM was shown to have a Cronbach alpha of .86.

\section{Mindful attention awareness scale}

The MAAS $^{46}$ is a self-report measure of dispositional mindfulness that has been validated among college students and community samples of adults. This measure consists of 15 items that focus on the absence of mindful attention and awareness, and takes $<5 \mathrm{~min}$ to complete. Items include statements such as "I find it difficult to stay focused on what's happening in the present" and "I rush through activities without being really attentive to them," and participants rate their responses on a 6-point scale $(1=$ almost always to $6=$ almost never $)$. The MAAS has high internal consistency with Cronbach alphas ranging from .80 to .90 , high test-retest reliability, as well as discriminant, convergent, and criterion validity. $\frac{46}{-}$ In this study, the MAAS was shown to have a Cronbach alpha of .87.

\section{Procedure}

Once ethics approval was obtained, advertisements were posted throughout the university inviting students who experience test anxiety to participate in a study in which they will learn a strategy to help them manage their test anxiety. Once the study dates were confirmed, students 
This is an Accepted Manuscript of an article published by Taylor \& Francis in 'Journal of American College Health' on 2019-03-25, available online: https://www.tandfonline.com/10.1080/07448481.2019.1583239.

arrived to a designated classroom in groups of approximately 8 participants. Students were randomly assigned to a mandala, free draw/color, or noncoloring control group in separate rooms. The researcher provided all students with blank envelopes that included all of the questionnaires and either a structured mandala, a blank sheet of paper for free draw/coloring, or a control activity sheet. The control activity consisted of a sheet of paper with 100 numbers, letters, and symbols at the top of the page, and a table with 100 spaces at the bottom of the page. Instructions for this activity were for participants to place the numbers, letters and symbols in the boxes at the bottom of the page in the order of their choice. The papers in the envelopes were only visible and opened by the students once the study began. Students were informed that they would receive their test results upon completion of the study.

Once students read the consent forms and provided signed informed consent to participate, the researcher read through the oral script summarizing the study. Both the consent forms and oral script informed students that they would be completing a section of an achievement test, and that they will receive the results of the test and recommendations for improvement upon completion of the study. Participants then completed both the STAI and the state MAAS. The researcher read through the directions with the students and instructed them to respond to each item truthfully. Students in the mandala and free condition were provided with colored pencils. The mandala group colored in the same structured mandalas for $15 \mathrm{~min}$ and the free group was invited to free draw/color on a blank sheet of paper for $15 \mathrm{~min}$. Participants in the control group were instructed to place the numbers, letters, and symbols in the boxes at the bottom of the page in any order of their choice over a 15-min period. Following the 15-min allotted to these activities, all participants completed the same test anxiety and state mindfulness 
This is an Accepted Manuscript of an article published by Taylor \& Francis in 'Journal of American College Health' on 2019-03-25, available online: https://www.tandfonline.com/10.1080/07448481.2019.1583239.

measures to assess postintervention test anxiety and state mindfulness. The researcher read through the instructions with the participants to maintain consistency at all times.

The researcher then read through the instructions for the spelling section of the Wide Range Achievement Test (WRAT-4), which all participants completed. To assess dispositional mindfulness, students completed both the CAMM and the MAAS. Upon completion of the study, participants were debriefed on the purpose of the study and received a debriefing sheet to take home, as well as $\$ 10$ as compensation. Once the data was coded and entered, each participant received a summarized group score for the spelling test and test anxiety questionnaires. Each student's spelling and test anxiety score was summarized and given to them, as well as resources and suggestions for literacy and writing development, and anxiety management.

\section{Results}

\section{Participants}

Participants were 167 students ( $81.4 \%$ female; $M_{\text {age }}=21.29$ years, $\left.S D=4.46\right)$ from a university in Montreal, Quebec, Canada. Participants were randomly assigned to each condition. An a priori power analysis indicated that a total sample of 113 participants was required to obtain a desired power of .80 for detecting a medium effect size with 3 groups when employing the traditional .05 criterion for statistical significance. There were 57 participants in the mandala group, 58 participants in the free/draw group, and 52 participants in the noncoloring control group. The groups were not significantly different according to participants' age and gender (see Table 1). The majority of the participants reported a program of study in the Faculty of Arts (43.7\%), followed by the Faculty of Science (15.6\%), the Faculty of Engineering (6\%), the 
This is an Accepted Manuscript of an article published by Taylor \& Francis in 'Journal of American College Health' on 2019-03-25, available online: https://www.tandfonline.com/10.1080/07448481.2019.1583239.

Faculty of Education (5\%) the Faculty of Agriculture and Environment Science (3.6\%), Arts and Science (3.6\%), and the Faculty of Management (3\%). The remaining students reported that they studied in the Faculties or Schools of Nursing, Epidemiology, Computer Science, Dentistry, Medicine, Nutrition, Biology, Physiology, Environment (8.4\%), or unspecified (11.1\%).

All data were analyzed with SPSS version 20. A total of 18 missing values were found in the dataset. Examination of missing data revealed that all variables had $<5 \%$ of missing values. To maintain the sample size in the 3 different groups, the Estimation Maximization procedure was conducted to impute the missing data. Prior to running the main analyses, all relevant assumptions were checked and verified. The mandala, free, and control group were not significantly different according to participants' age, preintervention test anxiety and preintervention state mindfulness scores; therefore, these variables were not controlled for in all further analyses (Table 1).

The first objective was to compare the effectiveness of coloring structured mandalas and free draw/coloring with a noncoloring control activity on students' test anxiety. Correlations between the dependent variables, postintervention test anxiety and state mindfulness were assessed prior to conducting the main analyses. A significant negative correlation was found, $r=$ $-.55, p<.01$; therefore, these 2 variables were both considered in the following analysis.

To test the effect of the 3 activities on postintervention test anxiety and state mindfulness scores, a repeated measures Multivariate Analysis of Variance (MANOVA) was conducted, with Time (pre and postintervention) and Test (test anxiety and state mindfulness) entered into the analyses. Results revealed a significant main effect for Time, $F(1,164)=23.04, p<.001$, Wilk's $\Lambda=.877$, partial $\eta^{2}=.123$, and 2 significant 2-way interactions between Time (pre to 
This is an Accepted Manuscript of an article published by Taylor \& Francis in 'Journal of American College Health' on 2019-03-25, available online: https://www.tandfonline.com/10.1080/07448481.2019.1583239.

postintervention) and Test (test anxiety and state mindfulness) $F(1,164)=29.43 p<.001$, Wilk's $\Lambda=.848$, partial $\eta^{2}=.152$, and Time and type of activity (mandala, free draw/color, control), $F(1$, 164)=13.76, $p<.001$, Wilk's $\Lambda=.856$, partial $\eta^{2}=.144$. Furthermore, a significant 3 -way interaction between Time, Test, and type of activity was uncovered, $F(1,164)=15.76, p<.001$, Wilk’s $\Lambda=.839$, partial $\eta^{2}=.161$.

To examine the effects of the 3 activities on test anxiety and state mindfulness, post hoc analyses were conducted. Results from 2 separate repeated measures Analysis of Variance (ANOVA) revealed significant differences for Time for test anxiety pre-postintervention, $F(1$, 164)=26.49, $p<.001$, Wilk's $\Lambda=.861$ partial $\eta^{2}=.139$, and for state mindfulness prepostintervention, $F(1,164)=24.88, p<.001$, Wilk's $\Lambda=.868$, partial $\eta^{2}=.132$. Furthermore, significant interactions were found between Time and type of activity for test anxiety, $F(1,164)$ $=14.91, p<.001$, Wilk's $\Lambda=.846$, partial $\eta^{2}=.154$, and for state mindfulness, $F(1$, 164)=7.41, $p<.01$, Wilk's $\Lambda=.917$, partial $\eta^{2}=.083$. As demonstrated in Figure 1a, participants in the mandala and free condition reported significant decreases in test anxiety scores prepostintervention; however, participants in the control condition reported increases in test anxiety pre-postintervention. In addition, participants in the mandala and free condition reported significant increases in state mindfulness pre-postintervention, whereas participants in the control condition did not show this change (Figure 1b).

The second objective was to assess the role of dispositional mindfulness on response to mindfulness intervention pre-postactivity. Preacher and Hayes ${ }^{48}$ procedure was used to perform all mediation analyses. Given that the control condition did not show significant changes in test anxiety or state mindfulness from pre to postintervention, only the mandala and free conditions 
This is an Accepted Manuscript of an article published by Taylor \& Francis in 'Journal of American College Health' on 2019-03-25, available online: https://www.tandfonline.com/10.1080/07448481.2019.1583239.

were included in the following analyses $(n=115)$. Tables 2 and 3 display the significant correlations between the variables entered into the 2 mediation analyses.

To remain consistent with the studies conducted in elementary $\underline{14}$ and high school, 11 the mediation analyses were first performed with the CAMM as a measure of dispositional mindfulness. Given that the sample of students in this study were neither children nor adolescents, the mediation analyses were then conducted with the MAAS to triangulate the data.

First, the role of preintervention state mindfulness on dispositional mindfulness (CAMM) and postintervention state mindfulness was assessed. Results revealed a significant positive effect of dispositional mindfulness on preintervention state mindfulness (path $\mathrm{a} ; b=.053, p<.001, \mathrm{CI}[.027, .078])$, which indicates that higher reports of dispositional mindfulness were associated with higher reports of preintervention state mindfulness. A significant positive effect was found from preintervention state mindfulness to postintervention state mindfulness (path $\mathrm{b} ; b=.650, p<.001, \mathrm{CI}[.520, .781]$ ), and the total effect of dispositional mindfulness on postintervention state mindfulness was also significant (path $\mathrm{c} ; b=.047, p<.001$, CI[.023, .071]). The direct effect of dispositional mindfulness on postintervention state mindfulness was not significant when controlling for preintervention state mindfulness (path $\left.c^{\prime} ; b=.013, p=.194, \mathrm{CI}[-.007, .032]\right)$. The indirect effect of dispositional mindfulness on postintervention state mindfulness through preintervention state mindfulness was significant $(a b=.034, \mathrm{CI}[.019, .051])$, which suggests a full mediation; specifically, preintervention state mindfulness fully mediates the relation between dispositional and postintervention state mindfulness (Figure 2a). 
This is an Accepted Manuscript of an article published by Taylor \& Francis in 'Journal of American College Health' on 2019-03-25, available online: https://www.tandfonline.com/10.1080/07448481.2019.1583239.

The same mediation analysis was then performed with the MAAS as a measure of dispositional mindfulness. Similarly, a significant positive effect of dispositional mindfulness on preintervention state mindfulness was found (path a; $b=.469, p<.001$, CI[.246, .693]), as well as a significant positive effect from preintervention state mindfulness to postintervention state mindfulness (path $\mathrm{b} ; b=.678, p<.001, \mathrm{CI}[.546, .810])$. The total effect of dispositional mindfulness on postintervention state mindfulness was significant (path $\mathrm{c} ; b=.331, p<.05$, CI[.112, .550]), and the direct effect of dispositional mindfulness on postintervention state mindfulness was not significant when controlling for preintervention state mindfulness (path $\left.c^{\prime} ; b=.013, p=.880, \mathrm{CI}[-.157, .481]\right)$. The indirect effect of dispositional mindfulness on postintervention state mindfulness through preintervention state mindfulness was significant $(a b=.318, \mathrm{CI}[.188, .481])$, which further demonstrates a full mediation (Figure 2b).

A mediation analysis examining the role of preintervention test anxiety on dispositional mindfulness (CAMM) and postintervention test anxiety was conducted. The effect of dispositional mindfulness on preintervention test anxiety was significantly negative (path a; $b=-$ $.676, p<.001, \mathrm{CI}[-.899,-.453])$ with higher levels of dispositional mindfulness associated with lower levels of preintervention test anxiety. The effect of preintervention test anxiety on postintervention test anxiety was significantly positive (path $\mathrm{b} ; b=.693, p<.001, \mathrm{CI}[.546$, $.840])$. The total effect of dispositional mindfulness on postintervention test anxiety was significant (path $\mathrm{c} ; b=-.613, p<.001, \mathrm{CI}[-.846,-.379]$ ), and when controlling for preintervention test anxiety, the direct effect of dispositional mindfulness on postintervention test anxiety was not significant (path c'; $b=-.144, p=.160, \mathrm{CI}[-.346, .058]$ ). The indirect effect of dispositional mindfulness on postintervention test anxiety through preintervention test anxiety was significant $(a b=-.469, \mathrm{CI}[-.693,-.294])$; as a result, preintervention test anxiety was found 
This is an Accepted Manuscript of an article published by Taylor \& Francis in 'Journal of American College Health' on 2019-03-25, available online: https://www.tandfonline.com/10.1080/07448481.2019.1583239.

to fully mediate the relation between dispositional mindfulness and postintervention test anxiety (Figure 2c).

The same mediation analysis was then performed with the MAAS. The effect of dispositional mindfulness on preintervention test anxiety was significantly negative (path a; $b=-$ $4.21, p<.001, \mathrm{CI}[-6.31,-2.11])$. The effect of preintervention test anxiety on postintervention test anxiety was significantly positive (path $\mathrm{b} ; b=.736, p<.001, \mathrm{CI}[.599, .874]$ ), and the total effect of dispositional mindfulness on postintervention test anxiety was significant (path c; $b=-$ $3.39, p<.05, \mathrm{CI}[-5.58,-1.21])$. When controlling for preintervention test anxiety, the direct effect of dispositional mindfulness on postintervention test anxiety was not significant (path $\left.c^{\prime} ; b=-.290, p=.730, \mathrm{CI}[-1.95,1.37]\right)$; however, the indirect effect of dispositional mindfulness on postintervention test anxiety through preintervention test anxiety was significant $(a b=-3.10$, CI[-5.05, -1.42]), further demonstrating a full mediation (Figure 2d).

To understand the full mediation, post hoc analyses were conducted. To elucidate if the changes in mindfulness and test anxiety states differs according to participants' level of dispositional mindfulness, change scores from pre to postintervention were computed for state mindfulness and test anxiety. The correlation between dispositional mindfulness and change in state mindfulness pre-postintervention was not significant (CAMM: $r=-.053 ; p=.573$ ) MAAS: $r=-.147, p=.117)$. Similarly, the correlation between dispositional mindfulness and change in test anxiety pre-postintervention was not significant (CAMM: $r=.063, p=.506$; MAAS: $r=.093 ; p=.324)$. As such, the degree of dispositional mindfulness was not significantly related to the degree of change pre-postintervention.

\section{Discussion}


This is an Accepted Manuscript of an article published by Taylor \& Francis in 'Journal of American College Health' on 2019-03-25, available online: https://www.tandfonline.com/10.1080/07448481.2019.1583239.

The purpose of this study was to examine the effectiveness of a mindfulness-based coloring activity for test anxiety among university students. Specific objectives were to (1) compare the effectiveness of mandala coloring, free/draw coloring and a noncoloring control activity on students' test anxiety and state mindfulness, and (2) evaluate the role of dispositional mindfulness on response to mindfulness intervention pre-postintervention.

In this study, findings indicated that participants in the mandala and free conditions reported significant decreases in test anxiety and significant increases in state mindfulness following the coloring interventions, which is consistent with the elementary and high school studies. For the first time, this study included a noncoloring control condition, and participants in this control group did not show these changes in mindfulness or test anxiety states prepostintervention. Most interestingly, students in the noncoloring control condition reported significant increases in test anxiety pre-postintervention, with no changes in state mindfulness. These findings suggest that both coloring activities are more effective than a noncoloring control activity for students' test anxiety and mindfulness states.

Previous research on the effectiveness of these activities has been inconsistent; although studies revealed that coloring mandalas and free coloring were equally effective for reducing test anxiety among youth, $\stackrel{14}{\underline{14}}$ and decreasing anxiety among university students, $\stackrel{15}{\underline{1}}$ other studies have shown that mandala coloring was more effective than free coloring on anxiety reduction. $\underline{10}, \underline{13}$ This study contributes to the body of literature documenting the potential effect of these interventions. Previous evidence of the effectiveness of mandala and free coloring could be criticized for potentially being due to a time or repeated testing effect; specifically, the passage of time pre to postintervention may impact students' response. These findings challenge that criticism by providing the first strong evidence that mandalas themselves are not more beneficial 
This is an Accepted Manuscript of an article published by Taylor \& Francis in 'Journal of American College Health' on 2019-03-25, available online: https://www.tandfonline.com/10.1080/07448481.2019.1583239.

for test anxiety or state mindfulness than free coloring, while simultaneously providing strong evidence of a potential effect that is not due to time or testing.

Coloring structured mandalas has been suggested to be a mindfulness-based activity as the structure of the circular design provides students with a sense of direction, attention, awareness, and organization in the moment, unlike free drawing or coloring; $;, 10,41$ however, recent studies have shown that free drawing and coloring can be equally effective as coloring mandalas for test anxiety and state mindfulness. ${ }^{11, \underline{14}}$ Given that these 2 coloring activities were more effective than engaging in a control activity, these findings further confirm that the structure of the mandala is not necessarily the only coloring method that can support students in managing their test anxiety and state mindfulness. Given that test anxiety is a concern among university students, and that they may even struggle with higher test anxiety than youth, ${ }^{16,17}$ these findings are particularly important for students as they progress through school. It is likely that university students are going to experience a number of tests and exams throughout their academic career; therefore, a 15-min coloring activity - either mandala or free - is a brief, simple, cost-effective, and easily accessible activity for them to participate in prior to a test.

The second objective of this study was to assess the mediating role of preintervention state mindfulness in the relationship between dispositional mindfulness and postintervention state mindfulness, as well as the mediating role of preintervention test anxiety in the relationship between dispositional mindfulness and postintervention test anxiety. Consistent with Carsley and Heath, ${ }^{11}$ preintervention state mindfulness was found to fully mediate relations between dispositional mindfulness and postintervention state mindfulness for students in both coloring conditions, and preintervention test anxiety fully mediated relations between dispositional mindfulness and postintervention test anxiety for students in both coloring conditions. 
This is an Accepted Manuscript of an article published by Taylor \& Francis in 'Journal of American College Health' on 2019-03-25, available online: https://www.tandfonline.com/10.1080/07448481.2019.1583239.

Post hoc analyses of the mediations revealed that the degree of change scores did not significantly differ according to dispositional mindfulness ratings. These findings differ from Carsley and Heath's ${ }^{11}$ study with adolescents, which revealed that participants' dispositional mindfulness affects their response to intervention. In Carsley and Heath's study with adolescents, participants were reporting high levels of dispositional mindfulness and were unable to experience the benefits of the test anxiety intervention; in contrast, results from this study show that regardless of whether participants indicated high or low dispositional mindfulness, they were still able to benefit in terms of test anxiety and state mindfulness pre-postintervention. Specifically, response to the intervention was not subject to the ceiling effect.

A number of explanations might account for these findings. First, in the high schools in which data was collected for Carsley and Heath's study, participants were exposed to other mindfulness activities in the school; therefore, it is possible that their experiencing of mindfulness states over time contributed to enhanced dispositional mindfulness. ${ }^{37,42}$ Alternatively, early adolescence may represent a developmental period in which individuals are more open to mindfulness training and certain brain regions and networks can be more easily modified. $\stackrel{49}{\underline{50}}$ As such, adolescents may be more likely to experience mindfulness compared to adults. Given that many institutions are incorporating mindfulness activities and

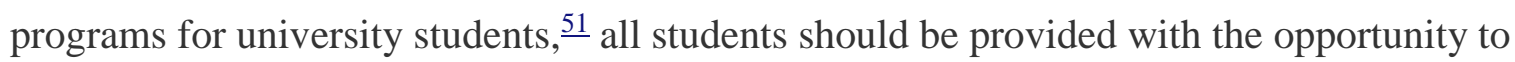
experience the benefits of the intervention, regardless of their individual dispositions. These results demonstrate that the ability for adults to benefit from coloring may not be limited to students with lower reports of dispositional mindfulness, and students who may experience high dispositional mindfulness are still benefitting in terms of state mindfulness and test anxiety after participating in these activities. 
This is an Accepted Manuscript of an article published by Taylor \& Francis in 'Journal of American College Health' on 2019-03-25, available online: https://www.tandfonline.com/10.1080/07448481.2019.1583239.

The findings in this study are not without limitations. First, similar to the previously conducted university studies, $\underline{10,13}$ the majority of participants in this study were female; therefore, it was not possible to examine gender differences. When compared with males, females tend to report higher trait test anxiety; $\underline{52,53}$ given that students who were recruited to participate in this study were more likely to experience test anxiety, this finding is not surprising. Future studies should include a more balanced gender sample to determine if the gender differences found in elementary and high school persist in university. Second, although we had clear decreases in test anxiety following the 2 coloring activities, this study took place in a controlled setting and did not include a test that was specific to what the students were studying. Future studies should include an actual testing situation to determine if this intervention is as effective with severe test anxiety. In addition, this study used a measure of state anxiety prior to a test. The majority of test anxiety measures assess traits of test anxiety; therefore, future studies should consider the effect of this intervention over time to accurately assess test anxiety traits in addition to test anxiety states. Third, it would be helpful to include a multiple factor measure of mindfulness. Although 2 measures of mindfulness were included in this particular study to triangulate the data, these measures are not multiple factor measures of mindfulness and future studies should consider examining the particular elements of mindfulness associated with these changes.

Despite these limitations, findings from this research provide practical implications for universities, students, and teachers, as well as future directions for research on mindfulnessbased art activities for test anxiety. Given that both coloring activities were effective for decreasing test anxiety and increasing mindfulness compared with a noncoloring control activity, students should consider engaging in one of these activities prior to completing a test. University mental health services can make students aware of these activities, particularly during stressful 
This is an Accepted Manuscript of an article published by Taylor \& Francis in 'Journal of American College Health' on 2019-03-25, available online: https://www.tandfonline.com/10.1080/07448481.2019.1583239.

periods such as final examinations, so students can access the materials prior to the test. Teachers who are looking to incorporate mindfulness activities into their course can also include these activities in their classes before a test or even as a calming moment with their students, as these activities consist of minimal resources and do not require any training. If a teacher is going to consider a universal classroom-based approach, future studies might want to examine how these types of activities can be helpful for students who are already mindful, but who still want to engage in mindfulness-based activities to enhance their experience of mindfulness.

This study represents the fourth school-based study that shows that mandala and free coloring are equally effective for supporting students' test anxiety; however, this is the first study to demonstrates that mandala and free coloring activities are more effective for test anxiety and mindfulness compared to a noncoloring control activity. Findings from this study further support the recommendation that mindfulness-based coloring prior to a test can be a helpful strategy to manage students' test anxiety, and students can continue to incorporate these simple activities when they are experiencing this type of anxiety within their lives. 
This is an Accepted Manuscript of an article published by Taylor \& Francis in 'Journal of American College Health' on 2019-03-25, available online: https://www.tandfonline.com/10.1080/07448481.2019.1583239.

\section{References}

1. Zenner C, Herrnleben-Kurz S, Walach H. Mindfulness-based interventions in schools-a systematic review and meta-analysis. Front Psychol. 2014;5(603):603. [PubMed], [Google Scholar]

2. Kabat-Zinn J. Mindfulness-based interventions in context: Past, present, and future. Clin Psychol-Sci Pr. 2006;10(2):144-156. [Crossref], [Google Scholar]

3. Arjunan NK, Joseph J. Brief mindfulness meditation based stress reduction programme in controlling examination anxiety of secondary school students. Int $J$ Indian Psychol. 2016;3(2):95-103. [Google Scholar]

4. Carsley D, Heath NL, Fajnerova S. Effectiveness of a classroom mindfulness colouring activity for test anxiety in children. J Appl Sch Psychol. 2015;31(3):239-255. [Taylor \& Francis Online], [Web of Science ${ }^{\circledR}$ ], [Google Scholar]

5. Napoli M, Krech PR, Holley LC. Mindfulness training for elementary school students. J Appl Sch Psychol. 2005;21(1):99-125. [Taylor \& Francis Online], [Google Scholar]

6. Dan O, Raz S. The relationships among ADHD, self-esteem, and test anxiety in young adults. $J$ Atten Disord. 2015;19(3):231-239. [Crossref], [PubMed], [Web of Science ®], [Google Scholar]

7. Lowe PA, Lee SW. Factor structure of the test anxiety inventory for children and adolescents (TAICA) scores across gender among students in elementary and secondary school settings. $J$ Psychoeduc Assess. 2008;26(3):231-246. [Crossref], [Web of Science ®], [Google Scholar]

8. Whitaker Sena JD, Lowe PA, Lee SW. Significant predictors of test anxiety among students with and without learning disabilities. J Learn Disabil. 2007;40(4):360376. [Crossref], [PubMed], [Web of Science $\left.{ }^{\circledR}\right]$, [Google Scholar] 
This is an Accepted Manuscript of an article published by Taylor \& Francis in 'Journal of American College Health' on 2019-03-25, available online: https://www.tandfonline.com/10.1080/07448481.2019.1583239.

9. Lowe PA, Lee SW, Witteborg KM, et al. The test anxiety inventory for children and adolescents (TAICA): Examination of the psychometric properties of a new multidimensional measure of test anxiety among elementary and secondary school students. J Psychoeduc Assess. 2008;26(3):215-230. [Crossref], [Web of Science ]], [Google Scholar]

10. Curry NA, Kasser T. Can coloring mandalas reduce anxiety? Art Ther J Am Art Ther. 2005;22(2):81-85. [Taylor \& Francis Online], [Google Scholar]

11. Carsley D, Heath NL. Effectiveness of mindfulness-based colouring for test anxiety in adolescents. School Psychol. Int. 2018;39(3):251-272. [Crossref], [Web of Science ®], [Google Scholar]

12. Beckwith P. Mindfulness and mandalas: Alternative therapeutic techniques for AOD adolescents. Capital Univ Undergrad Res J. 2014;n.a:1-5. [Google Scholar]

13. Van der Vennet R, Serice S. Can coloring mandalas reduce anxiety? A replication study. Art Ther J Am Art Ther. 2012;29(2):87-92. [Taylor \& Francis Online], [Google Scholar]

14. Carsley D, Heath NL. Evaluating the effectiveness of a mindfulness coloring activity for test anxiety in children. J Educ Res. 2018:1. [Taylor \& Francis Online], [Web of Science ®], [Google Scholar]

15. Mantzios M. Giannou When did coloring books become mindful? Exploring the effectiveness of a novel method of mindfulness-guided instructions for coloring books to increase mindfulness and decrease anxiety. Front Psychol. 2018;9(56). [Google Scholar]

16. Dan O, Ilan OB, Kurman J. Attachment, self-esteem and test anxiety in adolescence and early adulthood. Educ Psychol. 2014;34(6):659-673. [Taylor \& Francis Online], [Web of Science ®], [Google Scholar] 
This is an Accepted Manuscript of an article published by Taylor \& Francis in 'Journal of American College Health' on 2019-03-25, available online: https://www.tandfonline.com/10.1080/07448481.2019.1583239.

17. Peleg O. Test anxiety, academic achievement and self-esteem among Arab adolescents with and without learning disabilities. Learn Disability Q. 2009;32(1):11-20. [Crossref], [Web of Science ®], [Google Scholar]

18. Kieffer KM, Cronin C, Gawet DL. Test and study worry and emotionality in the prediction of college students' reasons for drinking: An exploratory investigation. J Alcohol Drug Educ. 2006;50:57. [Google Scholar]

19. Szafranski DD, Barrera TL, Norton PJ. Test Anxiety Inventory: 30 years later. Anxiety Stress Coping. 2012;25(6):667-677. [Taylor \& Francis Online], [Web of Science ${ }^{\circledR}$ ], [Google Scholar]

20. King NJ, Mietz A, Tinney L, Ollendick TH. Psychopathology and cognition in adolescents experiencing severe test anxiety. J Clin Child Psychol. 1995;24(1):49-54. [Taylor \& Francis Online], [Web of Science ${ }^{\circledR}$ ], [Google Scholar]

21. LeBeau RT, Glenn D, Liao B, et al. Specific phobia: A review of DSM-IV specific phobia and preliminary recommendations for DSM-V. Depress Anxiety. 2010;27(2):148167. [Crossref], [PubMed], [Web of Science $\left.{ }^{\circledR}\right]$, [Google Scholar]

22. Eum K, Rice KG. Test anxiety, perfectionism, goal orientation, and academic performance. Anxiety Stress Copin. 2011;24(2):167-178. [Taylor \& Francis Online], [Web of Science $\left.{ }^{\circledR}\right]$, [Google Scholar]

23. Segool N, Carlson J, Goforth A, von der Embse N, Barterian J. Heightened test anxiety among young children: Elementary school students' anxious responses to high-stakes testing. Psychol Schools. 2013;50(5):489-499. [Crossref], [Web of Science ${ }^{\circledR}$ ], [Google Scholar]

24. Hembree R. Correlates, causes, effects, and treatment of test anxiety. Rev Educ Res. 1988;58(1):47-77. [Crossref], [Web of Science ${ }^{\circledR}$ ], [Google Scholar] 
This is an Accepted Manuscript of an article published by Taylor \& Francis in 'Journal of American College Health' on 2019-03-25, available online: https://www.tandfonline.com/10.1080/07448481.2019.1583239.

25. Chapell MS, Blanding ZB, Silverstein ME, et al. Test anxiety and academic performance in undergraduate and graduate students. J Educ Psychol. 2005;97(2):268-274. [Crossref], [Web of Science ${ }^{\circledR}$ ], [Google Scholar]

26. Tobias S. Anxiety research in educational psychology. J Educ Psychol. 1979;71(5):573582. [Crossref], [Web of Science $\left.{ }^{\circledR}\right]$, [Google Scholar]

27. Ergene T. (2003). Effective interventions on test anxiety reduction: A meta-analysis. School Psychol Int. 2003;24(3):313-328. [Crossref], [Web of Science ®], [Google Scholar]

28. Beidel DC, Turner SM. Comorbidity of test anxiety and other anxiety disorders in children. $J$ Abnorm Child Psychol. 1988;16(3):275-287. [Crossref], [PubMed], [Web of Science ®], [Google Scholar]

29. Bodas J, Ollendick TH. Test anxiety: A cross-cultural perspective. Clin Child Fam Psychol Rev. 2005;8(1):65-88. [Crossref], [PubMed], [Web of Science ®], [Google Scholar]

30. McDonald AS. The prevalence and effects of test anxiety in school children. Educ Psychol. 2001;21(1):89-101. [Taylor \& Francis Online], [Google Scholar]

31. Wren DG, Benson J. Measuring test anxiety in children: Scale development and internal construct validation. Anxiety Stress Copin. 2004;17(3):227-240. [Taylor \& Francis Online], [Web of Science ${ }^{\circledR}$ ], [Google Scholar]

32. Von der Emse N, Barterian J, Segool N. Test anxiety interventions for children and adolescents: A systematic review of treatment studies from 2000-2010. Psychol Schools. 2013;50:5771. [Crossref], [Web of Science ${ }^{\circledR}$ ], [Google Scholar]

33. Ramirez G, Beilock SL. Writing about testing worries boosts exam performance in the classroom. Science. 2011;331(6014):211-213. [Crossref], [PubMed], [Web of Science ®], [Google Scholar] 
This is an Accepted Manuscript of an article published by Taylor \& Francis in 'Journal of American College Health' on 2019-03-25, available online: https://www.tandfonline.com/10.1080/07448481.2019.1583239.

34. Carsley D, Khoury B, Heath NL. Effectiveness of mindfulness interventions for mental health in school: A comprehensive meta-analysis. Mindfulness. 2018;9(3):693-707. [Crossref], [Web of Science ${ }^{\circledR}$ ], [Google Scholar]

35. Cunha M, Paiva MJ. Text anxiety in adolescents: The role of self-criticism and acceptance and mindfulness skills. Span J Psychol. 2012;15(2):533-543. [Crossref], [PubMed], [Web of Science ®], [Google Scholar]

36. Burke CA. Mindfulness-based approaches with children and adolescents: A preliminary review of current research in an emergent field. J Child Fam Stud. 2010;19(2):133-

144. [Crossref], [Web of Science $\left.{ }^{\circledR}\right]$, [Google Scholar]

37. Kiken LG, Garland EL, Bluth K, Palsson OS, Gaylord SA. From a state to a trait: Trajectories of state mindfulness in meditation during intervention predict changes in trait mindfulness. Pers Indiv Differ. 2015;81:41-46. [Crossref], [PubMed], [Web of Science $\left.{ }^{\circledR}\right]$, [Google Scholar]

38. Shapiro SL, Oman D, Thoresen CE, Plante TG, Flinders T. Cultivating mindfulness: Effects on well-being. J Clin Psychol. 2008;64(7):840-862. [Crossref], [PubMed], [Web of Science ®], [Google Scholar]

39. Abbott KA, Shanahan MJ, Neufeld RWJ. Artistic tasks outperform nonartistic tasks for stress reduction. Art Ther J Am Art Ther. 2013;30(2):71-78. [Taylor \& Francis Online], [Google Scholar]

40. Barrett CA. Adult coloring books: Patterns for stress relief. Phi Kappa Phi Forum. 2015;95(4):27. [Google Scholar]

41. Henderson P, Rosen D, Mascaro N. Empirical study on the healing nature of mandalas. Psychol Aesthet Crea. 2007;1(3):148-154. [Crossref], [Google Scholar] 
This is an Accepted Manuscript of an article published by Taylor \& Francis in 'Journal of American College Health' on 2019-03-25, available online: https://www.tandfonline.com/10.1080/07448481.2019.1583239.

42. Shapiro SL, Brown KW, Thoresen C, Plante TG. (2011). The moderation of mindfulness-based stress reduction effects by trait mindfulness: Results from a randomized controlled trial. J Clin Psychol. 2011;67(3):267-277. [Crossref], [PubMed], [Web of Science ${ }^{\circledR}$ ], [Google Scholar]

43. Flett JAM, Lie C, Riordan BC, Thompson LM, Conner TS, Hayne H. Sharpen your pencils: Preliminary evidence that adult coloring reduces depressive symptoms and anxiety. Crea Res J. 2017;29(4):409-416. [Taylor \& Francis Online], [Web of Science ${ }^{\circledR}$ ], [Google Scholar] 44. Spielberger CD. State-Trait Anxiety Inventory: A Comprehensive Bibliography. Palo Alto, CA: Consulting Psychologists Press; 1989. [Google Scholar]

45. Spielberger CD, Gorsuch RL, Lushene R, Vagg PR, Jacobs GA. Manual for the State-Trait Anxiety Inventory. Palo Alto, CA: Consulting Psychologists Press; 1983. [Google Scholar]

46. Brown KW, Ryan RM. The benefits of being present: Mindfulness and its role in psychological well-being. J Pers Soc Psychol. 2003;84(4):822-848. [Crossref], [PubMed], [Web of Science ®], [Google Scholar]

47. Greco LA, Baer RA, Smith GT. Assessing mindfulness in children and adolescents:

Development and validation of the child and adolescent mindfulness measure (CAMM). Psychol Assess. 2011;23(3):606-614. [Crossref], [PubMed], [Web of Science ${ }^{\circledR}$ ], [Google Scholar]

48. Preacher KJ, Hayes AF. SPSS and SAS procedures for estimating indirect effects in simple mediation models. Behav Res Methods Instrum Comput. 2004;36(4):717731. [Crossref], [PubMed], [Google Scholar]

49. Roeser RW, Pinela C. Mindfulness and compassion training in adolescence: A developmental contemplative science perspective. New Dir Youth Dev. 2014;2014(142):9-

30. [Crossref], [PubMed], [Google Scholar] 
This is an Accepted Manuscript of an article published by Taylor \& Francis in 'Journal of American College Health' on 2019-03-25, available online: https://www.tandfonline.com/10.1080/07448481.2019.1583239.

50. Roeser RW, Zelazo PD. Contemplative science, education and child development: Introduction to the special section. Child Dev Perspect. 2012;6(2):143-145. [Crossref], [Web of Science ®], [Google Scholar]

51. Bamber MD, Kraenzle Schneider J. (2015). Mindfulness-based meditation to decrease stress and anxiety in college students: A narrative synthesis of the research. Educ Res Rev. 2016;18:132. [Crossref], [Web of Science ${ }^{\circledR}$ ], [Google Scholar]

52. Eman S, Dogar IA, Khalid M, Halder N. Gender differences in test anxiety and examination stress. J Pakistan Psychiat Soc. 2012;9(2):85. [Google Scholar]

53. Nunez-Pena MI, Suarez-Pellicioni M, Bono R. (2016). Gender differences in test anxiety and their impact on higher education students' academic achievement. Soc Behav Sci. 2016;228:154160. [Crossref], [Google Scholar] 
This is an Accepted Manuscript of an article published by Taylor \& Francis in 'Journal of American College Health' on 2019-03-25, available online: https://www.tandfonline.com/10.1080/07448481.2019.1583239.

\section{Tables and Figures}

Table 1. Demographic information and preintervention test anxiety and state mindfulness scores across participant group.

\begin{tabular}{|l|c|c|c|c|}
\hline \multicolumn{1}{|c|}{ Variable } & Mandala & Free & Control & Significance test \\
& group & group & group & \\
\hline Gender, \% female & $82.50 \%$ & $75 \%$ & $86.20 \%$ & $\chi 2(1)=3.24, \mathrm{p}=$ \\
& & & & .072 \\
\hline Age, M (SD) & $21.21(4.88)$ & 21.74 & 20.90 & $\mathrm{~F}(2,164)=.49, \mathrm{p}=$ \\
\hline Test Anxiety (pre), M & $40.74(10.51)$ & 41.53 & 40.12 & $\mathrm{~F}(2,164)=.25, \mathrm{p}=$ \\
(SD) & & $(9.89)$ & $(11.41)$ & .78 \\
\hline State Mindfulness (pre), M & $4.41(1.05)$ & 4.15 & $4.30(1.26)$ & $\mathrm{F}(2,164)=.84, \mathrm{p}=$ \\
(SD) & & $(1.12)$ & & .43 \\
\hline
\end{tabular}


This is an Accepted Manuscript of an article published by Taylor \& Francis in 'Journal of American College Health' on 2019-03-25, available online: https://www.tandfonline.com/10.1080/07448481.2019.1583239.

Figure 1. Pre to post intervention (a) test anxiety scores and (b) state mindfulness scores in the free, mandala, and control conditions.
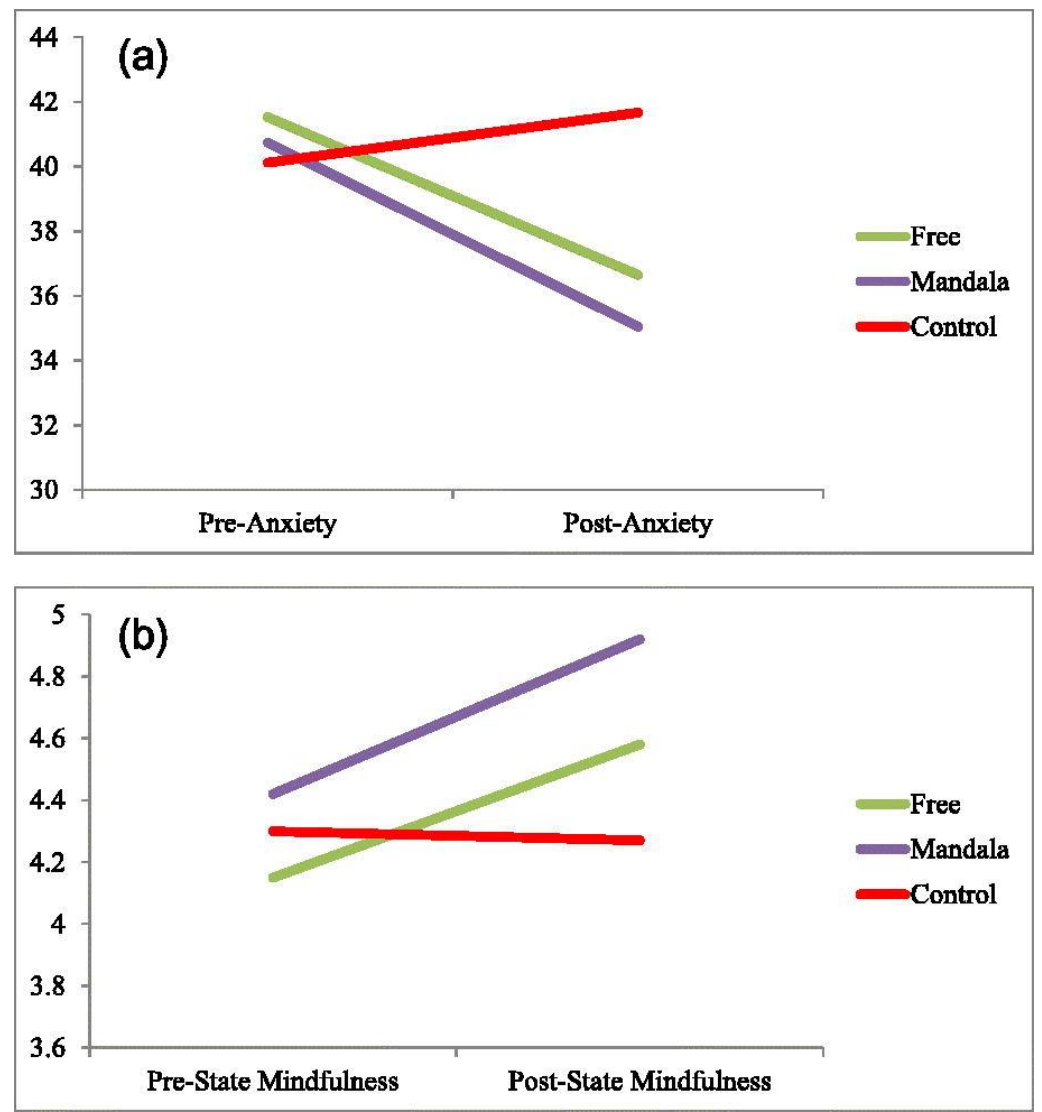

Table 2. Correlations between dispositional mindfulness, preintervention state mindfulness, and postintervention state mindfulness.

\begin{tabular}{|c|c|c|c|c|c|}
\hline & & 1 & 2 & 3 & 4 \\
\hline $\begin{array}{l}\text { 1. Dispositional mindfulness } \\
\text { (CAMM) }\end{array}$ & $\mathrm{r}$ & 1 & & & \\
\hline \multirow[t]{2}{*}{$\begin{array}{l}\text { 2. Dispositional mindfulness } \\
\text { (MAAS) }\end{array}$} & $\mathrm{r}$ & $.587 *$ & 1 & & \\
\hline & $\mathrm{n}$ & 115 & & & \\
\hline
\end{tabular}


This is an Accepted Manuscript of an article published by Taylor \& Francis in 'Journal of American College Health' on 2019-03-25, available online: https://www.tandfonline.com/10.1080/07448481.2019.1583239.

\begin{tabular}{|c|c|c|c|c|c|}
\hline \multirow[t]{2}{*}{$\begin{array}{l}\text { 3. Preintervention state } \\
\text { mindfulness }\end{array}$} & $r$ & $.358 *$ & $.364^{*}$ & \multirow[t]{2}{*}{1} & \\
\hline & $\mathrm{n}$ & 115 & 115 & & \\
\hline \multirow[t]{2}{*}{$\begin{array}{l}\text { 4. Postintervention state } \\
\text { mindfulness }\end{array}$} & $\mathrm{r}$ & $.337 *$ & $.271^{*}$ & $.720^{*}$ & \multirow[t]{2}{*}{1} \\
\hline & $\mathrm{n}$ & 115 & 115 & 115 & \\
\hline \multicolumn{6}{|c|}{$\begin{array}{l}\text { Note. } \text { CAMM }=\text { Child and Adolescent Mindfulenss Measure; MAAS = Mindful } \\
\text { Attention Awareness Scale. } \\
*_{n}<01\end{array}$} \\
\hline
\end{tabular}

Table 3. Correlations between dispositional mindfulness, preintervention test anxiety, and postintervention test anxiety.

\begin{tabular}{|c|c|c|c|c|c|}
\hline & & 1 & 2 & 3 & 4 \\
\hline $\begin{array}{l}\text { 1. Dispositional mindfulness } \\
\text { (CAMM) }\end{array}$ & $\mathrm{r}$ & 1 & & & \\
\hline \multirow[t]{2}{*}{$\begin{array}{l}\text { 2. Dispositional mindfulness } \\
\text { (MAAS) }\end{array}$} & $\mathrm{r}$ & $.587 *$ & 1 & & \\
\hline & $\mathrm{n}$ & 115 & & & \\
\hline \multirow[t]{2}{*}{ 3. Preintervention test anxiety } & $\mathrm{r}$ & $-.492 *$ & $-.350^{*}$ & \multirow[t]{2}{*}{1} & \\
\hline & $\mathrm{n}$ & 115 & 115 & & \\
\hline \multirow[t]{2}{*}{ 4. Postintervention test anxiety } & $\mathrm{r}$ & $-.440^{*}$ & $-.278^{*}$ & $.734 *$ & \multirow[t]{2}{*}{1} \\
\hline & $\mathrm{n}$ & 115 & 115 & 115 & \\
\hline
\end{tabular}


This is an Accepted Manuscript of an article published by Taylor \& Francis in 'Journal of American College Health' on 2019-03-25, available online: https://www.tandfonline.com/10.1080/07448481.2019.1583239.

Note. CAMM = Child and Adolescent Mindfulenss Measure; MAAS = Mindful Attention Awareness Scale.

Figure 2. (a) The mediating effect of preintervention state mindfulness in the association between dispositonal mindfulenss (CAMM) and postintervention state mindfulness. (b) The mediating effect of preintervention state mindfulness in the association between dispositonal mindfulenss (MAAS) and postintervention state mindfulness. (c) The mediating effect of preintervention test anxiety in the association between dispositonal mindfulenss (CAMM) and postintervention test anxiety. (d) The mediating effect of preintervention test anxiety in the association between dispositonal mindfulenss (MAAS) and postintervention test anxiety. Standardized path coefficients are shown in parentheses. CAMM $=$ Child and Adolescent Mindfulenss Measure; DM = dispositional mindfulness; MAAS = Mindful Attention Awareness Scale; PreSM = preintervention state mindfulness; PostSM = postintervention state mindfulness; PostTA $=$ postintervention test anxiety; PreTA $=$ preintervention test anxiety $\left(n=193 .{ }^{*} p<.001\right.$, $* * p<.05)$. 
This is an Accepted Manuscript of an article published by Taylor \& Francis in 'Journal of American College Health' on 2019-03-25, available online: https://www.tandfonline.com/10.1080/07448481.2019.1583239.
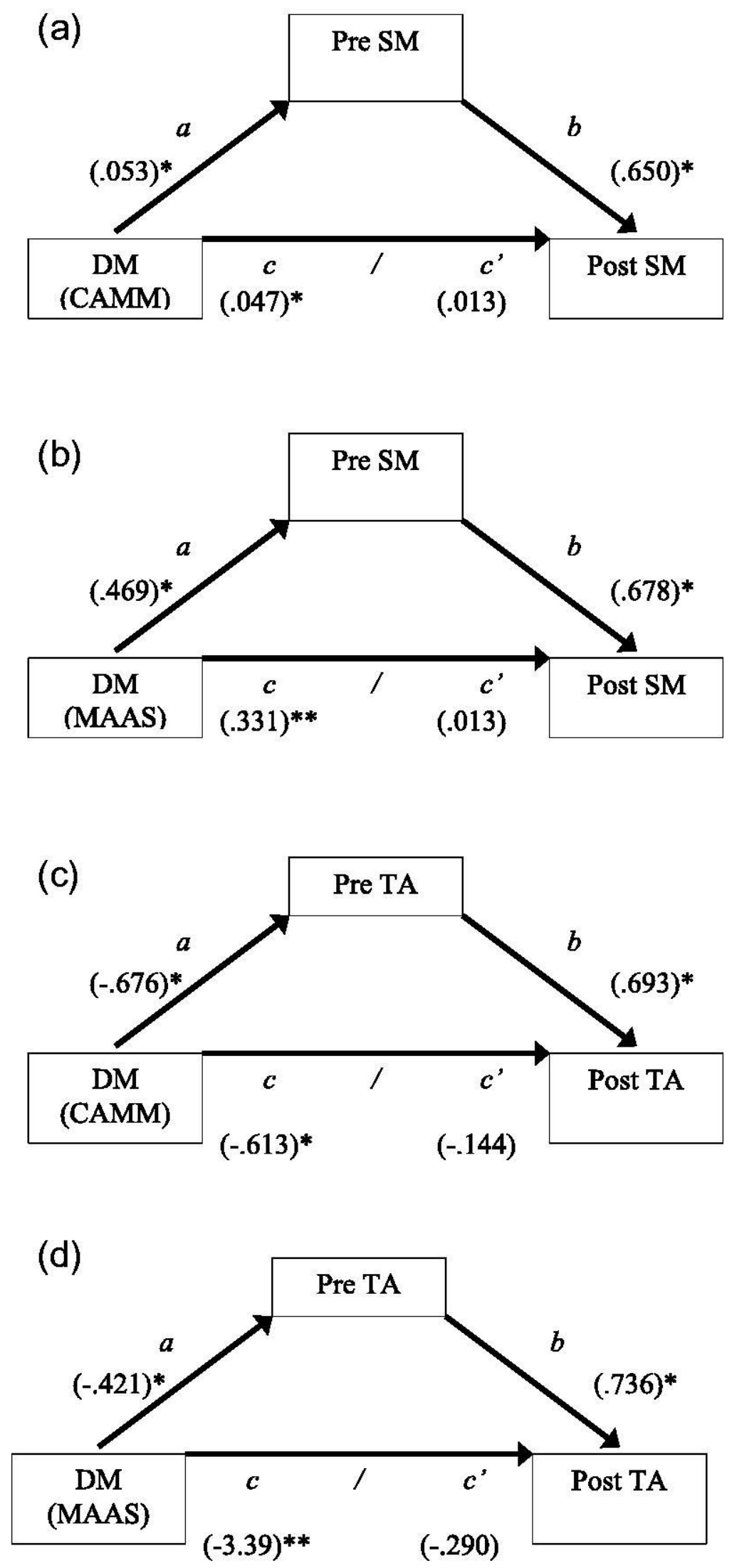